ARTÍCULO OPINIÓN

\title{
Encaminados a la reducción del cáncer cervicouterino en Honduras
}

\author{
Aimed at reducing cervical cancer in Honduras
}

Heriberto Rodríguez Gudiel, ${ }^{1}$ Maura Carolina Bustillo. ${ }^{2}$

${ }^{1}$ Médico Especialista en Ginecología y Obstetricia, Sub-especialista en Medicina Materno Fetal; Sub-Dirección Médica, Hospital de Especialidades San Felipe; Universidad Católica de Honduras, Tegucigalpa.

${ }^{2}$ Médico Especialista en Ginecología y Obstetricia, Departamento de Ginecología y Obstetricia, Hospital Escuela; Facultad de Ciencias Médicas UNAH, Tegucigalpa.

El primer artículo que la Revista Médica Hondureña (RMH) dedicó al tema de cáncer en un análisis de la situación nacional, fue publicado en 1982 en el número 50, donde los galenos Carlos Bueso y Julio Castillo realizaron un resumen de tesis doctoral coordinados por el Dr. Danilo Alvarado, en el cual se proporcionó información estadística hasta ese momento inédita de la situación del cáncer en Honduras. ${ }^{1}$ En ese reporte (19691979), el cáncer cervicouterino ocupó la mayor frecuencia de casos de cáncer en la mujer (53.6\%), seguido del cáncer de piel $(8.7 \%)$ y mama $(6.4 \%)$.

La revisión del estado actual del cáncer en Honduras analizado por los médicos J. Ángel Sánchez, Flora Duarte y Rafael Mojica, publicado en el volumen 60, Número 4, del año 1992, compiló la información publicada en la RMH hasta ese año (8 artículos) junto a 19 tesis de grado de la Universidad Nacional Autónoma de Honduras, mencionándose que para la década de los años 80 , el cáncer más frecuente presentado en las estadísticas que incluían ambos sexos, seguía siendo el cáncer cervicouterino, los cuales eran en su mayoría detectados en estadios avanzados de la enfermedad. ${ }^{2}$ En el mismo volumen se describió el resultado del estudio de biopsia de conización cervical por los galenos Moradel, Crespin y Aguilar, quienes encontraron que el $60 \%$ de pacientes sometidas a conización nunca se había realizado una prueba de tamizaje; entre otros hallazgos, $11.8 \%$ de las lesiones encontradas presentaron un grado de microinvasión. ${ }^{3}$

En el año 2005, en el volumen 73, Número 2, la Dra. Silvana Varela, publicó una revisión sobre la citología cervical como método de tamizaje, haciendo énfasis en la necesidad de unificar la técnica de toma de la misma y proporcionar una guía para la interpretación adecuada del informe citológico, introduciendo el sistema de Bethesda, el cual es en la actualidad la guía utilizada para describir los resultados. ${ }^{4}$ Ya en esa revisión se puntualizó la baja sensibilidad de la citología para la detección de cáncer cervico-

Recibido: 06-02-2020; Aceptado para publicación 01-03-2020

Dirección para correspondencia: Dra. Carolina Bustillo

Correo electrónico: mcbu1502@yahoo.com

Declaración de relaciones y actividades financieras y no financieras y conflictos de interés: ninguna.

DOI: https://doi.org/10.5377/rmh.v88iSupl.1.11679 uterino, 0.51 , con una especificidad de 0.98 , contando con que se realiza una adecuada técnica para la toma de la muestra.

La adopción de las pruebas de tamizaje a nivel poblacional se ha asociado con una marcada reducción en la incidencia de cáncer cervical en países desarrollados. Gran cantidad de evidencia implica a la infección por tipos de alto riesgo de virus papiloma humano como agentes causales en cáncer cervicouterino. Mientras la mayoría de las infecciones se resuelven sin consecuencias clínicas en periodos variables, ${ }^{5}$ la infección persistente puede llevar a una lesión precursora de alto grado de las cuales alrededor de $30 \%$ puede progresar a cáncer invasor, en periodos tan prolongados como hasta 30 años. .,6 $^{5,}$

Esta ventana amplia para la detección de lesiones cervicales de alto grado abre la oportunidad para el tamizaje adecuado y oportuno, así como el tratamiento de las lesiones. Las estrategias de tamizaje son variadas; la citología cervical, inspección visual con ácido acético, prueba de Lugol y la combinación de ellas se utilizan ampliamente. La detección de virus papiloma humano de alto riesgo (hrHPV) en muestras cervicales, ha mostrado tener una mayor potencialidad de detectar lesiones de alto riesgo y mayores comparado a la citología; sin embargo, aunque ambos pueden tener falsos positivos, hay mayor frecuencia de referencia a colposcopia y sobre tratamiento con el uso del hrHPV. ${ }^{7}$ La Secretaría de Salud de Honduras recientemente actualizó el protocolo de detección y las pautas para el manejo y referencia de pacientes con lesiones cervicales asociadas a virus papiloma humano, permitiendo estrategias que amplíen la cobertura hasta regiones de difícil acceso y movilización para las usuarias quienes muchas veces no pueden acceder a una atención por médico especialista, clínicas de colposcopia y estudios de anatomía patológica, lo anterior sumándose a la estrategia de vacunación a niñas que inició en mayo de 2016 con la vacuna cuadrivalente que protege contra la infección por los dos virus de alto riesgo asociados al $70 \%$ de casos de lesiones de alto grado y de cáncer.

Desde el 2018, la Secretaría de Salud con la cooperación técnica de OPS/OMS implementa acciones para fortalecer los servicios de diagnóstico y tratamiento del cáncer cervicouterino en apoyo a las acciones de la Secretaría de Salud que para 2018 reportó la tasa de cáncer cervicouterino de 29.4/mil 
habitantes, con 991 nuevos casos por año. Con apoyo de la OPS/OMS y el Programa para la Tecnología Apropiada en la Salud (PATH por sus siglas en inglés), se realizó un estudio piloto de detección de hrHPV en la Región Metropolitana y los Departamentos de El Paraíso y Copán, encontrando 14.4\% de resultados positivos, lo cual representa una oportunidad para la prevención primaria. $^{8}$
Queda por delante un largo camino por recorrer, ya que el cáncer cervicouterino sigue siendo el cáncer más frecuentemente diagnosticado en la población femenina, pero se han dado pasos seguros y concretos, plantándose las bases para la modernización de los sistemas de detección temprana hacia la reducción de la incidencia de cáncer cervicouterino en Honduras.

\section{REFERENCIAS}

1. Bueso CE, Castillo JC, Alvarado D. Cáncer en Honduras, 1969-1979. Rev Med Hondur. 1982; 50(3):136-147.

2. Sánchez JA, Duarte F, Mojica R. Estado actual, prevención y manejo del cáncer en Honduras. Rev Med Hondur. 1992; 60(4):171-177.

3. Moradel MA, Crespín MA, Aguilar O. Conización del cuello uterino en patología cervical. Rev Med Hondur. 1992; 60(4): 163-166.

4. Varela S. Citología cervical. Rev Med Hondur. 2005; 73(3):131-136.

5. Sawaya GF, Smith-McCune K, Kupperman M. Cervical Cancer ScreeningMore Choices in 2019. JAMA. 2019; 321(20): 2018-2019.

6. San José S, Broton SM, Pavón MA. La historia natural de la infección de virus papilloma humano. Best Pract Research Clin Obstet Gyn. 2018; 47: 2-13.

7. US Preventive Services Task Force. Screening for cervical cancer with high-risk human papillomavirus testing. JAMA. 2018; 320 (7): 687-705.

8. Organización Panamericana de la Salud, Organización Mundial de la Salud. Crea un futuro sin cáncer cervicouterino [internet]. Tegucigalpa: OPS/OMS; 2020. [acceso 8 de febrero de 2020]. Disponible en: https:// www.paho.org/hon/index.php?option=com_content\&view=article\&id=16 64:crea-un-futuro-sin-cancer-cervicouterino-el-momento-de-actuar-esahora\&ltemid $=260$ 